\title{
DIGITAL STORYTELLING WITH GOSHTHI ${ }^{1}$
}

\author{
*Ankita Nandy, **Rashmi Kujur \\ *Research Associate, Bharti Institute of Public Policy, \\ Indian School of Business, Mohali, India \\ ** Supervisor, Integrated Child Development Services, \\ Ministry of Women and Child Development, Surajpur, Chhattisgarh
}

DOI: $10.37648 /$ ijrst.v10i01.001

Received:15 $5^{\text {th }}$ December, 2019; Accepted:20 $0^{\text {th }}$ January, 2020; Published: $14^{\text {th }}$ February,2020

\begin{abstract}
Almost all ancient civilizations have had a tradition of storytelling. This oral tradition has sustained the handover of valuable knowledge from generation to generation. The audience, especially the younger ones, used to assimilate diverse forms of articulation and varied opinions through these interactions, and become storytellers in their own walks of life. With the advent of the Internet, modern lifestyles and choice of leisure, exposure of this sort, through books and people, has significantly decreased. Although we receive vast amounts of audio-visual content on a single click, the ease of sharing them as posts, tweets and messages on a digital platform has made the need for reinterpretation and oral transmission obsolete. The penetration of smartphones, in both rural and urban areas, has diminished the need for face to face interactions to such extents that although we are forever connected, we are becoming less social.
\end{abstract}

As technology creates new distractions, new disruptions are required to combat them. Storytelling workshops are popular among students of all grades. However, the interaction is limited to the participants of the workshop, which are often of the same age and intellectual calibre, formal in approach and less diverse in terms of presentation styles. These limitations have a debilitating impact on the expressiveness and creativity and problem-solving abilities of the masses. This work aims to revive this tradition, widening the sphere of sharing, through the closed community of students and their teachers, within a school.

Goshthi is the proposed mobile app, creating a digital social platform for sharing audio. Taking cues from images presented in folk styles, or on hearing the narration of a folk tale, the students need to record a short story, which can vary in style, length and even interpretation. It can be paralleled in concept with a platform like Instagram, populated with audio instead of visual/audio-visual content. Its objective is to encourage articulation amongst students. The app facilitates peer to peer sharing and facilitates teachers in grading these recordings for cohesion, coherence and fluency. $B y$ restricting the activities to the school community, the app administrators can ensure that inappropriate content doesn' $t$ pollute the platform and parental trust and guidance can be gained and sustained. Unlike a physical workshop, it gives those shy of speaking in public or slow in composing their responses the privilege to express themselves in private, at their own pace, in their own languages.

Goshthi extends the language learning benefits of the ubiquitous Toastmasters' Clubs. Taking inputs from popular apps such as Duolingo, OpenTalk and Shootwords elements of gamification will be incorporated. The viewers' perception of image(s) is heavily influenced by the elements in their immediate surroundings, such as racism, abuse and violence, which show up in their expressions. Thus, manual analysis of their stories can help school counsellors detect warning signs and approach them with timely help. As we live in a vibrant, extremely competitive photoshopped world, visual content makes people more insecure and more depressed and less happy. Promoting interaction through non-visual media can be a refreshing change and divert the focus to more intellectual pursuits. It will be useful for intellectual growth, social support and confidence building.

Keywords : storytelling; non-cognitive skills; oral communication; digital learning; language learning

${ }^{1}$ How to cite the article: Nandy A., Kujur R., Digital Storytelling with Goshthi, IJRST, Jan-Mar 2020, Vol 10, Issue 1, 1-9, DOI: http://doi.org/10.37648/ijrst.v10i01.001 


\section{INTRODUCTION}

Contrary to the days where print media, radio and word-of-mouth used to be our sources of information, the introduction of digital platforms and easy access to the internet has shifted our sources to e-newspapers, automated feeds and social media platforms such as Twitter and Facebook [1]. These services keep us updated on the go and interesting content can be shared to a wider network over messaging apps, automated emails and the like, with a click or a tap.

Although this increased consumption and accessibility of information is a positive outcome of the digitization and connectivity in the society, a drawback is a decrease in avenues for consumers to comprehend, reinterpret and reproduce the cumulative information for others. Children mimic the surrounding elders and this seemingly harmless trend has a major impact on their interpersonal communication skills. In [2], the teachers in a middle school observe that students, though physically together, are engaged in their mobile phones, and the content on their phones directs the conversation. The anxiety of realtime face-to-face interactions give way to the "I prefer to text than talk" [3] behavior, wherein edited words frame open to interpretation opinions and create a sense of virtual control.

Following the Path of Least Resistance, it is likelier that they end up sharing the media via messaging apps, instead of sharing it as a spoken message. The ease of sharing information without speaking decreases their motivation as well as practice in oral transmission. [4] reports than over $40 \%$ of the rural population in India has access to a phone. As schools push the use of technology in education, the lack of casual talking can become a serious social issue in the coming years.

In the age of information overload, communication is a powerful tool to frame appealing questions that get readily answered. Strengthening the skills of oration, not just in terms of pronunciation and fluency but also in cohesion and lucidity of content, empowers the students with an indispensable skill in getting heard. The age-old tradition of storytelling proves to be a time-tested means in enhancing articulation skills.

As [5] notes, stories are around since the beginning of civilization, and humans have used them to pass on information about food sources, impending disaster, survival skills and codes of conduct. Over the centuries, storytelling has been refined to entertain royals, incite rebellion among masses and lull a toddler to sleep. Stories find ample applications in classrooms, boardrooms and political rallies alike.

To the children in the age group of 10-12 years and older, the world revolves around the supportive community of their teachers and parents. Although storytelling workshops and related extra-curricular activities to hone the oratory skills are regularly organized, the duration and physical space limit the participation of the whole community. Technological intervention, such as a storytelling app, can keep the community connected and invested in the skill enhancement of the students. By introducing game elements, a healthy competitive environment and increased engagement and entertainment can be ensured.

Across all genres and formats, the storyteller expresses his/her conflicts, experiences and desires, apprehensions et cetera through his/her work [6]. Thus, as the students record their versions of the story, they offer a glimpse into their emotional states. Through a survey of experienced social workers in residential homes for children, [7] gathers evidence of the therapeutic and cathartic nature of storytelling. They have been used to introspect and acknowledge loss and trauma and overcome emotional turbulences. As storytellers inject elements from their personal experiences, stories on Goshthi can serve as resources in identifying domestic violence and abuse, and guide counsellors to reach out to those affected.

This paper starts with a thorough review of related literature, followed by a discussion of the proposed application, the development methodology and potential outcomes.

\section{LITERATURE REVIEW}

As students today can access vast repositories of often conflicting information on the Internet, the role of a teacher has changed from source of knowledge to facilitator and moderator. Technology has been readily embraced to keep up with these changes. In accordance with these shifts, the learning process has been experimented with and revolutionized. The RASE (Resources- Activity- SupportEvaluation) learning model introduced in [8] chalks out the relationships and interactions for holistic learning in classrooms. The educator provides the learner with a challenge that incites him/her to explore the available resources and learn on the fly. She also moderates this activity and ensures that the learner doesn't deviate far from the right course of action. A system of evaluation is in place to track learner's progress and the effectiveness of the approach. 
With increased recognition of the importance of noncognitive skills, such as empathy and initiative, for growth of an individual, educational institutions are employing the wisdom of the masses to impart skills in language learning and communication [9]. Crowdsourcing assimilates the individual contributions of large groups to facilitate knowledge creation, problem-solving, resource sharing. It has successful examples such as Amazon Mechanical Turk (https://www.mturk.com/), Khan Academy (https://www.khanacademy.org/), Peer to Peer University P2PU (https://www.p2pu.org/en/) et cetera catering to millions of users in numerous ways worldwide. [10] discusses the application of crowdsourcing in academia and research under four heads.

- Knowledge sharing. Wikipedia is a repository of information built by millions of contributors, who add a piece from their experiences and understanding to complete the bigger picture. This keeps educational aids from becoming outdated in this rapidly changing world.

- Problem-solving. FoldIt (http://fold.it/portal/) in research and Threadless (https://www.threadless.com/) in fashion has benefitted from the ideas of the masses. Many amateurs and professionals participate; the problem is approached with different perspectives and the overall solution are better than those from some expert brains. [11]

- Crowdfunding. This is a practice of making an open call to investors to come and contribute small amounts towards a research project or entrepreneurial venture, and get social, monetary or material in return, determined by various financing and investment models [12].

- Building public opinion. Open-to-all surveys are efficient tools to analyze and measure the collective response of the masses towards policy changes, fashion and other commonplace trends, which forms the foundation of further research.

Accessing crowdsourcing educational resources, such as edX (https://www.edx.org/), reduces the costs in acquiring a skill and adds personalization which may be limited in traditional classroom environments [13]. P2PU platform integrates online resources with physical classrooms to bring in the best of virtual and real interactions in [14].

In addition to the dynamism of content, the mode of instruction has been revolutionized with gamification. It is the trend of including game elements in the realm of nongaming contexts and has been built on principles like purpose, empowerment, ownership, social connectivity, curiosity and impatience. It has found successful applications in diverse fields such as retail, governance and education [15]. As [16] puts it, games have been an escape from mundane reality into virtual worlds with greater meaning, with and without digital intervention, since centuries. Such widespread is the "gaming" phenomenon, that instead of resisting it, jumping on the bandwagon and gamifying reality has led to greater engagement and motivation in users.

[17] mentions the use of badges, points, levels, mission, gifts and virtual goods, which sometimes can be traded for material, monetary and social rewards in the real world. With experimental gamification of a course on Algorithms and Programming Languages, consumers of gamified content recorded greater satisfaction compared to those of the non-gamified content. [18] analyzed the impact of gamified quizzes on learner's retention across university courses on sciences and accounting to present a broader picture.

\section{METHODOLOGY}

Software Development Life Cycle (SDLC) delineates the stages of development of a software application. There are seven broad stages (Figure 1), which can be executed linearly, or iteratively, as per the demands of the application under construction. To distribute the resources according to the requirements of and monitor the progress in each stage, frameworks are built and refined. The Agile methodology of SDLC facilitates quicker delivery of the product and rapid responses to errors and alterations. SCRUM is a popular Agile methodology that has been incorporated into this project [19]. It demarcates the roles and responsibilities of the people involved and organizes the tasks on different scales of time, such as daily, monthly et cetera, thus measuring and monitoring the overall progress closely. With the vision of offering the schools ample opportunities to customize the product and ensure a short development cycle, SCRUM has been selected. 
1. Survey and analyse the problem

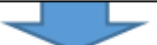

2. Study existing systems

3. Determine the needs of potential users

4. Select the best solution

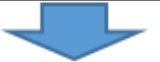

5. Determine the hardware and software requirements

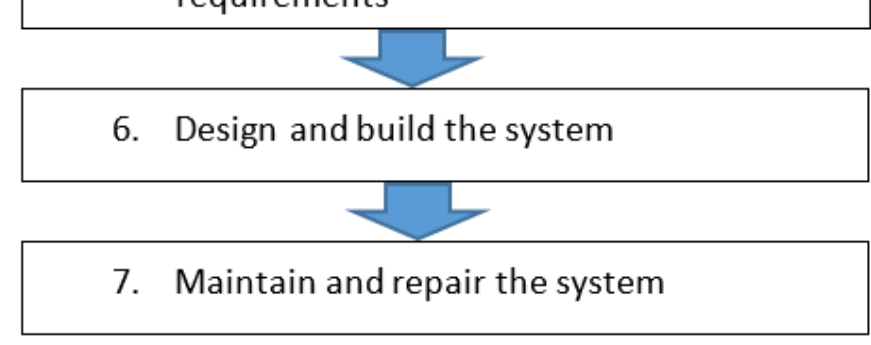

Figure 1. Flowchart for SDLC process

1. Survey and analyze the problem.

The process of development starts with observing and analyzing the problem to be solved and planning towards a solution.

Studies conducted by the [20] found that the though print enjoys considerable popularity, $47 \%$ of the surveyed use electronic devices like e-readers, mobiles and computers to access magazines, newspapers and books. Though print remains popular, in 2016 the studies indicated $28 \%$ and $14 \%$ users consuming information on e-books and audiobooks, respectively. The Indian Readership Survey [21] conducted annually since 1995 indicates the shift from print to digital. People consume news on digital channels over the years. While it was at 9 per cent in 2017, it has gradually risen to $13.8 \%$ and $15.1 \%$ respectively, in the first two quarters of 2019. These numbers are still small and seem less of a threat, however, as digital devices discreetly enter our homes and children are exposed to such devices from an early age, applying the Zipf Principle of Least Effort, just like the consumption the sharing of information is digital as well.

In a study of Americans, [2] found a preference for texting over talking across all age groups. The exchange of easily edited messages may seem easier and more peaceful than direct confrontations, however, all they do is put a superficial mask on the issue and leave the real underlying problem unresolved. [22] surveyed 17 teenagers hailing from rural and urban backgrounds to analyse their patterns of accessing information through technology and found that mobile phones have become critical in maintaining interpersonal relationships and feel lost and disconnected if their phones are lost, damaged or unavailable for other reasons. One of the participants remarked, "I'm always looking at it, putting it away, looking at it, putting it away, all the time." [23]. What they are looking at- as the survey reported- are social networking sites followed by messengers.

While very few studies focus on the Indian user, emerging behavioural patterns in developed countries in $[2,22]$ indicate the severity of the issue in the coming years and its impact on the social. Technological interventions to prepare the teenagers of today to actually "talk", without becoming overly dependent on their messaging applications, are required. This may not cure their cell phone addictions, however, reduce the damage this trend can have on their social skills.

2. Study existing systems

Extempore App, (https://extemporeapp.com/), is a cloud-based platform connecting students and teachers for oral assignments and assessments. Developed in 2016, it can be used independently or as an extension to learning management systems such as Blackboard and Moodle. In response to activities organised by the instructor, the learner records an oral response, which is scored based on 
parameters related to the learning objective(s). Targeted at foreign language courses, it was built with the motive of making students speak more in the language they learn. The online connectivity ensures the instructor and the learner need not be face-to-face in order to practice speaking.

Duolingo (https://www.duolingo.com/), launched in 2011, started out as a language learning application and has gained high momentum with numerous language courses, including fictional languages like Valyrian. It has benefitted from crowdsourcing in building vast translation resources. It has embraced gamification and artificial intelligence in offering learners an experience equating a full semester course material at a university, completely free.

Kahoot (https://kahoot.com/) is a gamified quizzing app, that adds the thrill of gaining points and racing against one's classmates. Its generic nature makes it useful across all courses. Instructors compile a set of questions with multiple options, which appear on the presenter's screen. Participants use their smartphones to log in and answer the questions. Not only does this app liven mundane lectures with intermittent contests, as [24] demonstrates, it increases student's engagement and offers a practice to students, which reflects in his/her test scores.

Instagram (https://www.instagram.com/?hl=en) is a social media platform for sharing stories through visuals. With a mix of texts and graphics, it has found wide acceptance among digital users.

OpenTalk (https://opentalk.to/) facilitates the sharing of ideas as audio recordings. This platform lets people discuss myriad topics from news to personal experiences and connect with fellow users. Transcription of the recording is available with each snippet. Similar applications are HearMeOut (http://hearmeoutapp.in/) and Shootwords (https://shootwords.com/login) which are social media applications that work with audio, text and visuals. Unlike Instagram which gained quick popularity, HearMeOut could not gather the user base it needed, indicating a requirement for visuals to keep the user interested. A cumulative study of these six applications in gathering the features successful in instructional and social domains has laid the foundation for building Goshthi.

3. Determine the needs of the potential users

The stakeholders are identified as the school community and the parents. Authors of [25], through a survey of parents, discuss the common concerns in letting their use digital content such as interactive e-books. A quarter of the surveyed parents worry over inappropriate content and advertising fed to the children alongside the educational content. Keeping this in consideration, the platform will be restricted to the school community and be devoid of commercial advertising. This can ensure the parent knows every person the child interacts with and can approach in the event of unwelcome behavior.

[26] reports that on a global level, internet users spend on an average of 2 hours and 23 minutes daily on social media. The data tabulated in Table 1 indicates a sharp rise in the daily duration of social media usage from 2012 to 2016. Thereafter, the trend line stabilizes towards the global average of 143 minutes a day in 2019. However, like [22] reports, though teenagers keep their phones away, they are still engaged with the virtual world in their minds and get fidgety to access it again.

Table 1. Time spent by Indian users on social media apps daily [25]

\begin{tabular}{c|ccccccccc}
\hline Year & 2012 & 2013 & 2014 & 2015 & 2016 & 2017 & 2018 & 2019 & 2019 Global Average \\
\hline Duration (in minutes) & 104 & 117 & 123 & 135 & 150 & 145 & 148 & 145 & $\mathbf{1 4 3}$ \\
\hline
\end{tabular}

Engaging students on their phones after school hours on an educational application can possibly reduce the time spent on social media and create a learning environment that covers classrooms and homes seamlessly. It can transform the concept of homework as well. Further, unlike Instagram and Facebook, where the criteria of competition are visual, users contest for high ratings over content and presentation of voice messages, which can be a refreshing change.
4. Determine the best solution.

The proposed application Goshthi is based on the RASE model [8], wherein the recorded stories/ visual cues are resources, the retelling is the activity, content moderation and feedback provide learning support, and a gamified system provide an overall assessment of the process.

It borrows features of social platforms- Instagram, HearMeOut and ShootWords, in offering options to form groups within the user base and leave a feedback or audio comment in response to another's post. From an 
instructional perspective, teachers have been empowered to prompt activities and request student participation. The content is censored by the administrator. Inspired from Duolingo and Kahoot, points and badges have been incorporated. To discourage the use of real photos, the concept of virtual identity or avatar is used. Aspects promoting healthy competition and creative expression have been included.

5. Determine hardware and software requirements

As per [4], there are 1188.89 million mobile subscribers in India. Teledensity understood as the number of telephones per 100 inhabitants, stands at 59.25 in rural areas. Though the number of Internet subscribers per 100 inhabitants in rural areas lags far behind the same figure in urban regions, we find that the gap between the percentages of telephone subscribers in rural and urban populations has narrowed down over the years. This information is presented in Table 2.

Table 2. Telecom User Statistics [4]

\begin{tabular}{l|llll}
\hline Year & 2015 & 2016 & $\mathbf{2 0 1 7}$ & $\mathbf{2 0 1 8}$ \\
\hline \multicolumn{5}{l}{ Telephone Subscribers (in percentage) } \\
\hline Rural & 41.77 & 42.27 & 41.99 & 43.40 \\
\hline Urban & 58.23 & 57.73 & 58.01 & 56.60 \\
\hline $\begin{array}{l}\text { Internet } \\
\text { Subscribers }\end{array}$ & (per & 100 \\
inhabitants) \\
\hline Rural & 12.89 & 12.80 & 15.49 & 16.41 \\
\hline Urban & 49.07 & 58.28 & 70.83 & 84.74 \\
\hline
\end{tabular}

With the rapid digitalization of the economy and the society, and public and private initiatives to increase the penetration of mobile phones and digital literacy, consumption of the Internet is deemed to rise. Similarly, as schools promote computer literacy, desktops with Internet connectivity will be available to several students. These mobiles and desktops, together with a basic microphone and speakers/headphones will be the hardware requirements for this platform.

The Goshthi application works on Android, thus the mobiles need to have this Operating System. On desktops, Windows environment is required. These operating systems have built-in sound players and voice recorders, otherwise, the corresponding drivers can be easily procured. Internet connectivity will be needed.

6. Design and implement

A user can perform three sets of operations on the application- listen to stories, record stories and provide feedback on existing stories. While stories for the purpose of listening do not require any login, other operations are accessible to logged-in users only.
The proposed system will require a secure login, using the e-mail ID, phone number, Aadhar number or any other school-issued identification, as convenient to the school authorities. The sign-up needs to be done using the desktop version, while later logins can be performed on any electronic device.

On the event of signup, the user needs to provide a username and create an avatar by selecting available features from a predefined library. This avatar will form the visual representation of the user. Thus, the user will neither have to upload pictures nor provide their real names. Such an approach can provide virtual anonymity to the users who might be dealing with favouritism, bullying or low self-esteem in their real lives.

Users can sign up with different roles: teacher/instructor/parent henceforth referred to as a guide, student and admin. While the admin has visibility to all content on the platform and powers to moderate the content and delete it if necessary, she/he has no powers to create content i.e. upload a new recording or provide feedback on existing content publicly. All the content on the platform needs to be approved by the admin before being visible to others. The platform offers the feature to create groups, as an example, for a certain grade or a club. Thus, apart from guide-student and student-student interactions, private groups including one or more student and zero or more guides can be formed, without a separate sign-up. All entities will be searchable by name.

The guides can upload voice recordings and visual cues to initiate retellings by the students. The visibility of the content will be limited to a certain duration, such as 3 months. At the end of this duration, the content though not visible on the feed, will exist on the database, and be accessible on admin's approval. This reduces the clutter on the user's feed. The goal of the application is to promote sharing however through voice. Thus, recordings on the platform cannot be downloaded or shared on or outside the platform as a media file.

The user gets a beginner badge on uploading the first recording. Pre-determined milestones such as 5th recording, 10th recording, 20th recording et cetera are felicitated by power badges, which give access more features from the visual library and enable the user to beautify his/her avatar.

The guides and the students can provide feedback to the recordings, other than their own, on a 5-point Likert scale, with 1 being very poor, 2 being poor, 3 being good, 4 being very good and 5 being excellent. They can upload additional feedback as a voice recording, which like all other content will be moderated by the admin. These ratings serve as points for the users, which accumulate with 
every recording the user uploads. An individual can track his/her progress through points. For groups, these points are used to create a leaderboard which is accessible on the desktop version.

The framework is presented in Figure 2. As audio recordings fall under the category of unstructured data, NoSQL database has been planned for this implementation. Cloud will be used for storage, allocated to a school community based on the estimated number of participants.
This database will interact with a platform that governs the contents, denoted as $\mathrm{Cn}$, where $\mathrm{n}$ can be any natural number, through a content manager and a feedback manager. The content manager deals with aspects such as the presentation, searchability, visibility and lifespan of the recording. The feedback manager controls the ratings and their relationship to the visual libraries. The user and administrator get different privileges in accessing and modifying the content.

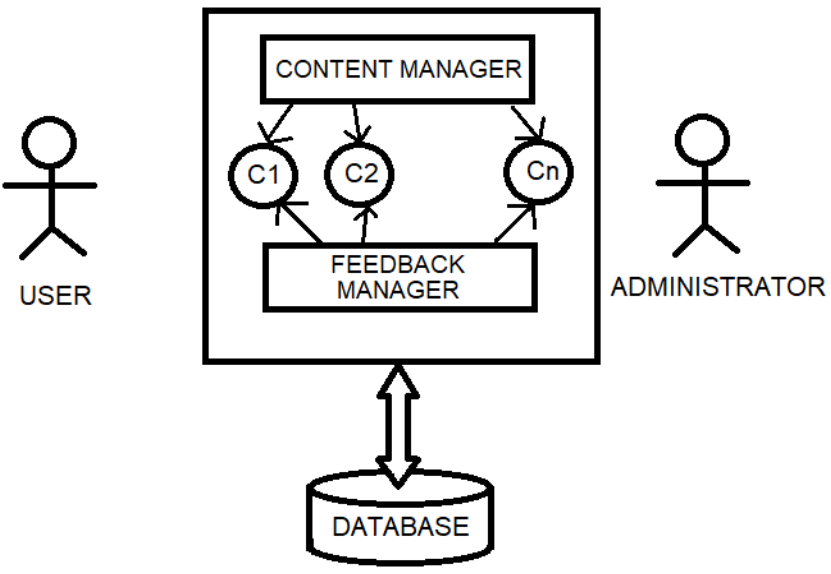

Figure 2. Goshthi Framework (Authors' Compilation)

India, with its long history, and cultural diversity boasts of a rich repository of stories captured in formats as varied as songs, riddles and dialogues. The language of assessment/ communication can be specified by the teacher in the instructions. With numerous languages spoken by people, unless specified explicitly, the user can choose his or her language of convenience.

7. Maintain and repair

The software needs continuous enhancement as per the expectations and experiences of the end-user. Thus, a lifetime technical support to the subscribing schools will be provided, with options to customize the aesthetics and security options on the platform.

\section{POTENTIAL OUTCOMES}

The proposed Goshthi app offers three operations for the user. The operation specific outcomes are listed as follows.

\section{Listening}

- Exposure to cultural heritage. Through storytelling, the children can explore diverse cultural aspects, mythology, belief systems and social practices. This in the long-term builds interest in broadening their minds.
- $\quad$ Exposure to multiple interpretations. Encouraging retelling of the stories offers varied perspectives of the same incidents and characters through different lenses. It makes the students stretch their imagination and creativity.

- Better moral lessons. Stories serve the essential task of reinforcing certain behavior and thought patterns, such as differentiating good and evil, obedience, helpfulness et cetera. Goshthi serves as an audio library of such stories.

Recording

- Improvement in language skills. The oral component of communication is an essential part of language skills. Like Extempore app and Duolingo, recording stories gives the user more practice speaking in a certain language, while at the same time ensuring they enjoy the content they talk about.

- Improvement in self-confidence. The proliferation of messaging applications makes the student more adept at texting while self-doubting in making a clear speech. As the students practice talking, they 
will feel more confident in communicating in public.

- A quickening of response. By adding time constraints, the teacher can encourage the user to frame a reply fast, with less hesitation and eventually inciting a spontaneous response.

Feedback

- Improvement in patience. In order to rate a recording, the user will be required to listen to it attentively till the end. This teaches the user patience.

- Oral assessment. The teachers can use the ratings to score vocabulary tests and oral assignments. These integrate with the game elements to motivate the students.

- $\quad$ Sportsmanship. Feedback creates an environment of healthy competition, inculcating sportsmanship.

As mentioned in [27], parents tend to give greater freedom in using smartphones to their sons, compared to their daughters. Considering the positive impact educational material on Internet can have on their education and overall intellectual development, the parental participation sought by Goshthi can alter the opinions of these parents and convince them to share digital resources with all their children, irrespective of gender.

\section{CONCLUSION AND FUTURE WORK}

Considering the impact of digital media on the social and language skills of the youth, this work merges the concepts and features of several popular applications on mobile and web and presents the Goshthi mobile app with the corresponding desktop version. It builds an after-school interaction platform for teachers, students and parents within a closed school community. The application lets users listen to, create and rate voice recordings in an easy to use a gamified environment. The expected outcomes of this application in the educational sphere are enhancement of fluency, development of retelling skills and exposure to the vast cultural bounties in the form of stories. Content is key to the learning value of the application. Diversifying the formats with animation clips as storytelling cues are planned. To increase its appeal to school-going children, the environment can be further gamified.

While currently a conceptual design, this application will be built and shared with school students. Responses from pilot studies and feedback from parents and teachers will contribute towards the enhancement of this platform. If successful, such novel designs can be extended to focus on other non-cognitive skills like team building and social bonding.

\section{REFERENCES}

[1] Aneez, Z., Neyazi, T. A., Kalogeropoulos, A., \& Nielsen, R. K., "Reuters Institute India digital news report”, Reuters Institute for the Study of Journalism/India Digital News Report, pp. 8, 2019.

[2] Turkle, S., "Reclaiming conversation: The power of talk in a digital age", New York: Penguin Press, 2015.

[3] Turkle, S., "Reclaiming conversation: The power of talk in a digital age”, New York: Penguin Press, pp. $22,2015$.

[4] Economics Research Unit - Statistics, Department of Telecommunications, "Telecom Statistics India-2018", Ministry of Communications, Government of India, New Delhi, 2018.

[5] Zipes, J., "The Cultural Evolution of Storytelling and Fairy Tales: Human Communication and Memetics", The Irresistible Fairy Tale, 1-20, 2012.

[6] Aras, G., "Personality and Individual Differences: Literature in Psychology-Psychology in Literature", ProcediaSocial and Behavioral Sciences, 185, 250-257, 2015.

[7] McLean, L., \& Tuite, E, "Stories and their value: Exploring the role of storytelling in social care practice", Scott. J. Resid. Child Care, 15, 29-45, 2016.

[8] Churchill, D., King, M., \& Fox, B., "Learning Design for Science Education in the 21st Century”, Zbornik Instituta za pedagoška istrazivanja/Journal of the Institute of Educational Research, 45(2), 2013.

[9] Khine, M. S.,"Non-cognitive skills and factors in educational success and academic achievement”, In Non-cognitive Skills and Factors in Educational Attainment (pp. 1-9). Brill Sense, 2016. 
[10] Solemon, B., Ariffin, I., Din, M. M., \& Anwar, R. M., “A review of the uses of crowdsourcing in higher education”, International Journal of Asian Social Science, 3(9), 2066-2073, 2013.

[11] Brabham, D. C., “Crowdsourcing as a model for problem solving: An introduction and cases”, Convergence, 14(1), 75-90, 2008.

[12] Bouncken, R. B., Komorek, M., \& Kraus, S., “Crowdfunding: The current state of research”, International Business \& Economics Research Journal (IBER), 14(3), 407-416, 2015.

[13] Jiang, Y., Schlagwein, D., \& Benatallah, B.,"A Review on Crowdsourcing for Education: State of the Art of Literature and Practice”, In PACIS (pp. 180), June 2018.

[14] Fellows, M., “The learning circle experience: Findings from the P2PU participant survey", Seattle: Technology \& Social Change Group, University of Washington Information School, 2018.

[15] Yfantis, V., \& Tseles, D., "Exploring Gamification In The Public Sector Through The Octalysis Conceptual Model”, 2017.

[16] McGonigal, Jane, "Reality is broken: why games make us better and how they can change the world", London: Jonathan Cape, 2011.

[17] Klock, A. C. T., Ogawa, A. N., Gasparini, I., \& Pimenta, M. S.,"Integration of Learning Analytics techniques and Gamification: an experimental study", In 2018 IEEE 18th International Conference on Advanced Learning Technologies (ICALT) (pp. 133-137), IEEE, 2018.

[18] Pechenkina, E., Laurence, D., Oates, G., Eldridge, D., \& Hunter, D., “Using a gamified mobile app to increase student engagement, retention and academic achievement", International Journal of Educational Technology in Higher Education, 14(1), 31, 2017.

[19] Permana, P. A. G., "Scrum method implementation in a software development project management", International Journal of Advanced Computer Science and Applications, 6(9), 198-204, 2015.

[20] Pew Research Center, "E-book Reading Jumps; Print Book Reading Declines.”, Washington, D.C. (December 27, 2012), (Retrieved through https://www.pewresearch.org/internet/2012/12/27/e-book-reading-jumps-print-bookreading-declines-2/ on 2nd October, 2019)

[21] Media Research Users Council, “Indian Readership Survey (IRS) ”, 2019.

[22] Brown, S. J., "Trends in Mobile Communication and Information Behaviours among Scottish Teenagers”, Dept. of Computer and Information Sciences, University of Strathclyde, 2014.

[23] Brown, S. J., "Trends in Mobile Communication and Information Behaviours among Scottish Teenagers", Dept. of Computer and Information Sciences, University of Strathclyde, pp. 35, 2014.

[24] Tóth, Á., Lógó, P., \& Lógó, E., “The Effect of the Kahoot Quiz on the Student's Results in the Exam”, Periodica Polytechnica Social and Management Sciences, 27(2), 173-179, 2019.

[25] Kucirkova, N., \& Littleton, K., "The digital reading habits of children. A national survey of parents' perceptions of and practices in relation to children's reading for pleasure with print and digital books", Art Council England, 2016.

[26] GlobalWebIndex, "Social Global Web Index's Flagship Report on the Latest Trends in Social Media",2019. (Retrieved through https://www.globalwebindex.com/reports/social on 20th December, 2019).

[27] Saikia, Mamta. Technology in Rural Schools, 2018. (Retrieved through https://www.bhartifoundation.org/blog/post/technology-in-rural-schoolson 7th November 2019). 